\title{
Diseño de una metodología para establecer la vocación turística de un destino. Caso Tuxtla Gutiérrez, Chiapas
}

\author{
Carolina Gómez Hinojosa \\ Universidad Nacional Autónoma de Chiapas \\ Carlos Mario Amaya Molinar \\ Universidad de Colima \\ Rodolfo Mundo Velásquez \\ Universidad Nacional Autónoma de Chiapas
}

\section{Resumen}

La palabra vocación se aplica con frecuencia a países, regiones, entidades o destinos turísticos, en escritos que van desde discursos públicos hasta artículos periodísticos, documentos oficiales y trabajos académicos; sin embargo, al explorar el tema, se encuentra que el término se usa con un significado laxo, en forma metafórica o imprecisa; algunos organismos de investigación y autoridades gubernamentales de diversos niveles han solicitado investigaciones sobre el tema. Por lo anterior, se decidió profundizar en el análisis, desarrollando trabajos de investigación documental y de campo, se buscó hasta los orígenes del concepto vocación, el cual, si bien no puede aplicarse directamente al campo del turismo, si pudo ser adaptado para diferenciar entre la disposición de recursos y atractivos en un territorio determinado y la de desarrollar la actividad turística. Para contrastar empíricamente los planteamientos, se realizó una investigación de campo en Tuxtla Gutiérrez, Chiapas, donde se encuestó a dos muestras: una de residentes del municipio y otra de turistas. El estudio empírico permite distinguir las diferencias entre los recursos y atractivos turísticos del territorio y la disposición de los agentes locales para aprovecharlos, así como las diferencias en las percepciones del potencial y la vocación turística de la región por la población y los turistas.

\section{Palabras clave}

Economía, percepción, residentes, turistas, vocación.

Recibido: 01/06/2013 · Aceptado: 07/09/2013 


\title{
Methodology to establish the tourism potential of a destination Case of Tuxtla Gutierrez, Chiapas, Mexico
}

\author{
Carolina Gómez Hinojosa \\ Universidad Nacional Autónoma de Chiapas \\ Carlos Mario Amaya Molinar \\ Universidad de Colima \\ Rodolfo Mundo Velásquez \\ Universidad Nacional Autónoma de Chiapas
}

\begin{abstract}
The word vocation is often used in relation to countries, regions, states and tourist destinations, in writings ranging from public speeches, to newspaper articles, official documents and academic papers; however, to explore the topic, the term is usually used with loose meanings, in metaphorical or inaccurate ways; some research organizations and government authorities at various levels have requested research on the subject. Therefore, to deepen the analysis, it was decided to perform documentary and field research, searching of the origins of the vocation term, which, although not directly applicable to the field of tourism, if it could be adapted to differentiate between available resources and attractions within a given territory and the willingness to develop tourism activity. To test empirically the proposal, we conducted a field study in Tuxtla Gutierrez, Chiapas, surveying two samples: one of township residents and another one of tourists. The empirical study distinguishes the differences between the resources and tourist attractions of the area and the willingness of local actors to exploit them, and differences in perceptions of the potential and tourist vocation of the region by residents and tourists.
\end{abstract}

\section{KEY WORDS}

Economy, perception, residents, tourists, vocation.

E-mail: mmtcarolina@yahoo.com.mx / cmamaya@ucol.mx / rmundo6@hotmail.com 


\section{Introducción}

La palabra vocación se aplica con frecuencia a países, regiones, entidades o destinos turísticos, en escritos que van desde discursos públicos hasta artículos periodísticos, documentos oficiales y trabajos académicos; sin embargo, al explorar el tema, se encuentra que el término generalmente se usa con un significado laxo, en forma metafórica o imprecisa. Por lo anterior y en atención a solicitudes de organismos de investigación y de algunas autoridades gubernamentales, se decidió profundizar en el análisis, desarrollando trabajos de investigación documental y de campo; algunos de sus resultados se presentan en este documento.

El término vocación surgió en el medio religioso, hace referencia a un llamado interno de servicio a la divinidad, significado que continúa utilizándose en ese ámbito. El vocablo vocación fue incorporado en los campos de estudios de las ciencias de la educación, la psicología y la gestión de los recursos humanos, en relación con los rasgos de personalidad, las aptitudes, los intereses y las intenciones de las personas, en función de la oferta de estudios profesionales y el mercado laboral, en aras de establecer una correspondencia entre las características de las personas y las aptitudes necesarias para desempeñarse apropiadamente en un campo profesional determinado.

Al analizar la literatura académica, general o turística, vemos cómo el término pasó de aplicarse a características de personas a territorios, países, regiones y ciudades, lo cual puede tener sentido en cuanto a rasgos y características espaciales, geográficos, culturales o naturales de los territorios, pero que carece de lógica si se pretendiera otorgar un significado de intención o interés de un territorio; resulta aún más complicado afirmar que una región determinada presenta un llamado para una acción o función en particular. Así, mediante el presente trabajo se busca responder a la siguiente pregunta: ¿Existe objetivamente la vocación turística de lugares, países, estados o ciudades? ¿Resulta epistemológicamente viable emplear el término? 
Para comprobar la existencia objetiva del constructo se realizó un estudio empírico en diversos municipios del estado de Chiapas. Para el caso de este trabajo, se presentan los resultados de dos encuestas aplicadas los días 18 y 19 de mayo en la ciudad de San Cristóbal de las Casas, Chiapas, mediante las cuales se obtuvieron 442 cuestionarios a turistas y 400 cuestionarios a residentes del municipio.

\section{El término vocación y la vocación turística}

\subsection{Origen del término vocación}

Para la Real Academia Española (2012) el término vocación proviene del vocablo latino vocatǐo, que significa acción de llamar, connotando una convocación o llamamiento, asociado con estados personales de fe vinculados a mensajes divinos para seguir una carrera religiosa y un comportamiento místico. Con un enfoque laico, desde el ámbito de las ciencias de la educación, el concepto alude a la inclinación de las personas hacia alguna profesión o carrera. El diccionario en línea Wordreference (2012) asocia a la vocación con nociones como preferencia, tendencia, inclinación, aptitud, afición, proclividad y gusto. El tesauro o diccionario ideológico en línea Merriam-Webster (2012) agrega otros significados usuales, como ocupación, funciones de individuos y grupos o áreas de actividad.

En el ámbito académico donde se originó el estudio del concepto, Schaefer (1984) afirma que el término vocación conlleva un significado religioso, pues se refiere a las decisiones personales más íntimas: destino y providencia, enlazándose con el término profesión, referido a lo que uno profesa, pues cada individuo es "llamado" a cierta tarea en la vida, tarea que corresponde con la expresión de la propia personalidad y con la autoimagen, el ser al que cada quien aspira; para este autor, la vocación concretiza esa necesidad de realización. Así, Schaefer (1984) continúa, la noción de vocación brinda un sentido romántico a las posibilidades de cada quien en la vida, pues quien ha acertado su vocación invierte su vida con la seguridad de que sus esfuerzos valen la 
pena, pues además del prestigio y el ingreso que una profesión pueden proporcionar, se tiene la sensación de ser necesitado.

Hankle (2010) asigna dos dimensiones al concepto vocación: una psicológica y otra espiritual. Desde la primera dimensión, el autor destaca cuatro teorías fundamentales de psicología vocacional. El autor inicia citando el trabajo de Parsons $(1909,2008)$, quien propone que la vocación de una persona es aquel trabajo que más se adecua a rasgos de personalidad, como las habilidades, aptitudes e intereses, que corresponden con tareas que deben desempeñarse en ocupaciones particulares; en este modelo, para que una vocación resulte exitosa, debe presentarse una correspondencia entre los requerimientos laborales y los rasgos de personalidad del individuo.

La segunda teoría sobre psicología vocacional mencionada por Hankle (2010) es la de Roe (1956), quien considera a la vocación como una elección subconsciente orientada a la supervivencia, en la cual se emplea la sublimación para obtener satisfacción psicológica en la carrera elegida, atendiendo al sacrificio que trabajar representa. El tercer modelo analizado por Hankle (2010) es el de Super (1972), recuperado por Osborne (1997); en este modelo, las elecciones vocacionales se realizan en la autocomprensión individual de los individuos, en su autoconcepto. Así, cuando el individuo se comprende a sí mismo, clarificando sus valores, busca una ocupación que lo satisfaga, con lo cual el trabajo se convierte en una extensión de la persona. El cuarto modelo vocacional revisado es el de Holland (1997), quien propone que diferentes tipos de personalidad se ajustan mejor a diferentes carreras, para lo cual construye seis tipos básicos de personalidad, definiendo el tipo de carrera al que mejor se adaptan. Finalmente, las teorías psicológicas sobre la vocación se refieren a la correspondencia entre diversos tipos de personalidad con diversos tipos de actividades laborales o profesionales.

\subsection{La vocación turística en la literatura académica}

Consultando la literatura académica, se encuentra que diversos autores emplean el término vocación turística sin definir con precisión su 
significado. Así, Pearce (1999) y Guizzardi y Mazzocchi (2010) emplean el término refiriéndose a rasgos, características o atractivos turísticos de sitios, mientras que Ritchie (1988) e Ishikawa y Fukushige (2007) se refieren a la ocupación o actividad económica de la población en un lugar dado. Edgell (1983) utiliza el término en el sentido clásico de elección de carrera u ocupación, aunque va un poco más allá, al asignar un papel a los gobiernos locales en la definición de la política turística en general, y educativa en particular, en cierta coincidencia con los planteamientos de Ritchie (1988) al respecto.

Massidda y Etzo (2012) tampoco definen el término vocación turística; sin embargo, sí emplean indicadores en un intento por medir el constructo; analizando su trabajo, resulta que más bien se refieren a un inventario de recursos turísticos o a la caracterización de la oferta y los atractivos turísticos de una región; lamentablemente, el diseño de su indicador sobre dotación de recursos turísticos no arrojó datos suficientemente confiables para ser considerado un parámetro representativo de la vocación turística.

En su calidad de director de la Oficina de Política y Planeación de la Administración de Turismo y Viajes de Estados Unidos de América, Edgell (1983) argumenta la necesidad de establecer políticas más coordinadas y mayores esfuerzos e inversiones para la atracción del turismo tanto en el nivel nacional como en el local, señalando que las autoridades estatales y locales definen los planes de estudios y la oferta educativa e, indirectamente, determinando si se ofrecen vocaciones turísticas a los estudiantes de educación superior y, de la misma manera, determinan si los estudiantes aprenden sobre los beneficios que el turismo trae a sus estados. Así, los contenidos de los cursos y de los materiales de estudio elegidos por los funcionarios educativos afectan las actitudes públicas hacia los turistas, hacia los trabajadores de las empresas turísticas y hacia el sector turismo en general.

Ritchie (1988) utiliza el término vocación turística al analizar el papel de la población residente en la formulación de políticas turísticas, comparando dos sitios; le atribuye una clara vocación turística al parque nacional Banff, con una importante participación de la población en la actividad turística, frente a una ciudad como Edmonton, más enfocada en actividades industriales; sin embargo, 
no presenta una definición del término. Entremezclando las concepciones religiosas con la modalidad de recursos turísticos, Pearce (1999) menciona la vocación de un lugar, comentando la vocación religiosa de un sitio en relación con su papel turístico, incluso etiquetando la vocación de dichos sitios religiosos / turísticos con señales o indicadores.

Ishikawa y Fukushige (2007) emplean el término vocación como sinónimo de ocupación, analizando las iniciativas de desarrollo turístico en la isla japonesa Anami Oshima, donde señalan que algunos de sus pobladores consideran que es tarea del gobierno municipal fomentar la actividad turística. Por su parte, Guizzardi y Mazzocchi (2010) se refieren a una fuerte vocación turística de Italia basada en centros turísticos ubicados en la fase de declinación de su ciclo de vida, señalando que, si bien se ubican en el octavo lugar de 176 países en la escala formulada por el Consejo Mundial de Viajes y Turismo en el 2007, también se ubica en el lugar número 173 en términos de expectativas de crecimiento, exhibiendo su vulnerabilidad frente a nuevos destinos turísticos.

En su artículo sobre determinantes del turismo doméstico en Italia, Massidda y Etzo (2012) mencionan el término vocación turística en varias ocasiones y, aunque no lo definen con precisión, sí emplean indicadores para medirlo como constructo. Para medir las diferencias regionales en el grado de vocación turística, los autores emplearon un índice orientado a medir la dotación relativa de sitios turísticos, asumiendo que elevados valores logrados en este indicador implican que en el área del destino existe una cantidad mayor de sitios turísticos en relación con la dotación nacional, con la expectativa de que el resultado se correlacionaría positivamente con el número de llegadas. Al final, los resultados relativamente pobres obtenidos en este indicador llevaron a los autores a concluir que la cantidad de sitios turísticos no influye decisivamente en los flujos de turismo doméstico o que el indicador no representa suficientemente el grado de vocación turística de una región específica.

Además de las definiciones encontradas en la literatura académica, en el Internet pueden encontrarse algunas definiciones simples de vocación turística, 
que explicitan significados que generalmente se dan implícitamente al término en la literatura académica, a pesar de lo cual no cuentan con un respaldo teórico o empírico. Entre estas definiciones sencillas se encuentran las de Valencia (2012): "Vocación turística: Inclinación de un área geográfica con atractivos turísticos que la destacan”; la del Ministerio de Comercio Exterior y Turismo de Perú (2012): "Son las características y potencialidades económicas, sociales, culturales y ecológicas que deben ser tomadas en cuenta por un destino para generar un aprovechamiento turístico óptimo del territorio" y la de Petrizzi (2011): "La vocación turística de un destino se define como la predisposición natural de un espacio o territorio para ser transformado en un lugar atractivo para potenciales visitantes."

Estas definiciones simples, basadas en la naturaleza, la cultura y el territorio, resultan poco consistentes si consideramos que, en la actualidad, la definición de los atractivos turísticos y el surgimiento de las corrientes turísticas pueden obedecer tanto a la existencia de atractivos naturales y culturales en un territorio determinado, como a modas, tendencias e intereses. Por ejemplo, el lugar donde actualmente se encuentra Las Vegas, Nevada, era un desierto despoblado y sin ningún tipo de aprovechamiento, motivo por el cual se autorizó la construcción de casinos, de la misma manera que hace cien años el turismo antártico resultaba inconcebible; lo mismo puede decirse del turismo "matrimonial" a Ucrania o del turismo médico.

Finalmente, al analizar la literatura académica general o turística, vemos cómo el término vocación pasó de aplicarse a características de personas a territorios, países, regiones y ciudades, lo cual puede tener sentido en términos de rasgos y características espaciales, geográficos, culturales o naturales de los territorios, pero que carece de lógica si se pretendiera otorgar un significado de intención o interés de un territorio dado, resultando aún más complicado afirmar que una región presenta un llamado para una determinada acción o función. Así entonces, puede concluirse que, de acuerdo con los resultados de la búsqueda realizada en este trabajo, hasta este momento no es posible afirmar con veracidad, objetividad y certeza que un territorio o destino turístico presentan una vocación para tal o cual función o actividad. Por lo demás, se comentó 
que Massidda y Etzo (2012) no obtuvieron resultados positivos al intentar equiparar vocación turística con inventario de atractivos o recursos turísticos.

Sin embargo, es posible intentar aplicar el término vocación, efectuando una extrapolación desde las ciencias de la educación, la psicología y la gestión de los recursos humanos al área de estudios del turismo, buscando equiparar los rasgos, aptitudes y características de las personas a las características, recursos naturales y culturales y atractivos turísticos de territorios, regiones y destinos turísticos, pero agregando los intereses, las intenciones y las capacidades de sus poblaciones, complementando estos factores con un análisis de su contexto sociodemográfico y de la demanda de servicios turísticos. Es importante, entonces, no confundir la existencia de atractivos o recursos turísticos con la vocación turística, pues, atendiendo al significado original del término, ésta se deriva de las intenciones de agentes o actores sociales de desarrollar, impulsar o promover la actividad turística.

En este contexto, es oportuno mencionar el papel que las clases dirigentes de una región o destino desempeñan en el impulso a la actividad turística. En el sector turístico mexicano, existen dependencias públicas federales, estatales y municipales cuya misión es el fomento a la actividad turística; en esos mismos niveles, existen organismos con participación pública y privada dedicados a esa función, al igual que organismos gremiales y empresariales, como cámaras, asociaciones y sindicatos de trabajadores dedicados a la operación turística. Todas estas dependencias y organizaciones participan en la operación turística y contribuyen en la formulación de políticas, planes y proyectos de desarrollo turístico en regiones, entidades federativas, municipios y destinos. Así, las iniciativas, planes y proyectos de desarrollo turístico pueden ser considerados indicadores de las intenciones y, por tanto, de la vocación turística de las clases dirigentes de una región.

Algunas preguntas de investigación que podrían formularse serían las siguientes:

- ¿Puede formularse el concepto vocación turística?

- ¿Es posible verificar empíricamente la existencia del constructo vocación turística? 
- ¿Cuáles son los factores que influyen directamente a la vocación turística de un país, región, ciudad o destino turístico?

- ¿Cuáles son los componentes de la vocación turística de un destino turístico, en caso de que existiera?

Recapitulando, de la revisión de la literatura arriba mencionada, puede afirmarse que la vocación turística de un destino o una región depende de los siguientes factores:

- Percepción de la importancia del turismo en la región

- Percepción de valor e importancia de atractivos y recursos turísticos en la región

- Intención de impulsar la actividad turística en la región

- Actitud de la población local frente al turismo y los turistas

- Intención de la población local de dedicarse al turismo

- Intención de estudiar carreras turísticas de los estudiantes de nivel medio

Así, entonces, para determinar la percepción de la vocación turística de un destino se diseñaron dos cuestionarios, uno dirigido a la población local y otro destinado a los visitantes; el instrumento dirigido a la población local incluye las siguientes dimensiones:

1. Interés de la población en participar y desarrollar la actividad turística en la región

2. Percepción del valor y la importancia de los atractivos y recursos turísticos de la región por la población

3. Percepción del potencial y la importancia del sector turismo para contribuir en la actividad económica y en la calidad de vida de la población

4. Percepción de la vocación turística de la región por los turistas

5. Actitud de la población local frente a la actividad turística y los turistas

6. Intención de los estudiantes de nivel de medio de estudiar carreras turísticas 
7. Impulso al turismo por dependencias públicas y organizaciones empresariales

El cuestionario dirigido a visitantes tiene como finalidad funcionar como medio de contraste de la percepción de la vocación turística de la población local y en él se incluyeron las siguientes dimensiones:

1. Importancia del turismo en la economía regional

2. Percepción del valor y la importancia de los atractivos y recursos turísticos de la región por la población

3. Percepción del potencial del sector turismo para contribuir en la actividad económica y en la calidad de vida de la población

4. Percepción de la vocación turística de la región por los visitantes

5. Disposición de la población local para mejorar la atención a los turistas

6. Actitud de la población local frente a los turistas.

\section{Metodología}

Para la obtención de la investigación de campo se empleó un procedimiento de muestreo no probabilístico, de conveniencia, aplicando 442 cuestionarios a residentes de la ciudad de Tuxtla Gutiérrez, Chiapas y, por otra parte, 400 cuestionarios más se aplicaron a turistas en la ciudad. El trabajo de campo se realizó en la segunda mitad del mes de mayo de 2013, entre los días 15 y 31. En el trabajo de campo y en la captura de la información se contó con la colaboración de estudiantes de la asignatura Investigación de Mercados, del sexto semestre de la Licenciatura en Gestión Turística que se imparte en la Facultad de Contaduría y Administración de la Universidad Autónoma de Chiapas. El instrumento de investigación se diseñó con la participación de integrantes de los equipos de las diversas instituciones involucradas en el proyecto. Antes de aplicar el cuestionario en forma definitiva, se manejaron 70 cuestionarios de prueba, 35 de cada modalidad, para asegurar la validez de su diseño; después de esta aplicación de prueba, se procedió a retroalimentar los instrumentos. Los 
datos recopilados mediante la aplicación de los instrumentos se capturaron en una base de datos y se procedió a su análisis estadístico.

El cuestionario dirigido a la población local reúne datos sobre diez variables, seleccionadas para obtener información sobre la vocación turística de la población, mientras que el instrumento dirigido a turistas presenta sólo seis variables; en ambos cuestionarios se empleó una escala de Likert de 5 grados; adicionalmente, se solicita información sobre las características sociodemográficas de la persona que responde.

\section{Resultados}

La ciudad de Tuxtla Gutiérrez es la capital del estado mexicano de Chiapas, ubicado al sureste de la república mexicana, colindando con la república de Guatemala, América Central. El municipio capitalino se localiza entre los paralelos $16^{\circ} 38^{\prime}$ y $16^{\circ} 51^{\prime}$ de latitud norte y los meridianos $93^{\circ} 02^{\prime}$ y $93^{\circ} 15^{\prime}$ de longitud oeste, presentando una altitud sobre el nivel del mar que va de los 200 a los 1500 metros (INEGI, 2009). Limita al norte con los municipios de San Fernando, Osumacinta y Chiapa de Corzo; al este con Chiapa de Corzo, al sur con Suchiapa y al suroeste con Ocozocoautla de Espinosa y Berriozábal. El municipio de Tuxtla Gutiérrez ocupa $0.46 \%$ de la superficie del estado, su clima es cálido subhúmedo con lluvias en verano, una temperatura que oscila entre los 20 y los $28{ }^{\circ} \mathrm{C}$ y precipitación pluvial que va de los 800 a los $1200 \mathrm{~mm}$; se ubica en la región hidrológica Grijalva-Usumacinta. En junio de 2012, la población del municipio ascendió a 553374 habitantes (INEGI, 2013), equivalente a $11.5 \%$ de la población estado, de los cuales $61.5 \%$ es población económicamente activa, encontrándose ocupada 95.6 \% ; la mayoría (82.3 \%) en el sector terciario y sólo $0.7 \%$ en el sector primario.

En el año 2011, un total de 640742 turistas se hospedaron en establecimientos de Tuxtla Gutiérrez, cantidad equivalente a 18.48 \% de los turistas que visitaron el estado de Chiapas en ese año; $94 \%$ de los turistas son de procedencia nacional. Durante el año mencionado, el porcentaje de ocupación hotelera en el municipio fue de $43.28 \%$, con una estancia promedio de 1.44 noches por turista (CEIEG, 2013). 


\subsection{Datos sociodemográficos de la muestra}

En el cuadro 1 se presentan datos sobre las características de la composición de las muestras (población residente y turistas) que respondieron las encuestas. En la población residente hay una mayor proporción de personas del sexo femenino, la mayoría son jóvenes de entre 18 y 34 años; en lo que se refiere a ocupación, se advierte una proporción importante de estudiantes, comerciantes y personas dedicadas a oficios diversos. En el mismo cuadro, en la muestra correspondiente a los turistas, se advierte un mayor equilibrio en lo relativo al sexo de los encuestados, aunque las edades también se concentran entre los 18 y 34 años, y se advierte una mayor proporción de personas con estudios de nivel superior y posgrado; con respecto a la procedencia, la mayoría de los entrevistados residen en el Distrito Federal, en el propio estado de Chiapas y en las vecinas entidades de Veracruz, Tabasco y Oaxaca; algunos son turistas extranjeros, pero en una proporción menor a la registrada en el municipio por el ceigh en el año 2011.

\subsection{Resultados de las encuestas}

\subsubsection{Encuesta a residentes de Tuxtla Gutiérrez}

Se presenta en primer lugar la información obtenida mediante la aplicación de la encuesta a la población y, enseguida, los resultados de la encuesta a turistas. Para ambas encuestas, en cada una de las variables investigadas se presenta un resultado promedio y la desviación estándar, calculados a partir de los resultados en sus diversos ítems. Para ilustrar el análisis, si la escala de Likert de 5 puntos se tradujera a una escala de diez, el resultado más alto en la encuesta a residentes lo obtendría la percepción de la actitud de la población local frente a los turistas, con 4.13 en Likert, que equivaldría a una calificación de 8.26; a este resultado sigue la percepción del valor y la importancia de los atractivos y recursos turísticos de la región por la población, con 4.12, seguida por la percepción del potencial del sector turismo para contribuir en la actividad económica y en la calidad de vida de la población, con 4.02. 
Cuadro 1. Características de la muestra

\begin{tabular}{|c|c|c|c|c|c|}
\hline \multicolumn{3}{|c|}{ Residentes } & \multicolumn{3}{|c|}{ Turistas } \\
\hline \multirow[t]{2}{*}{ Sexo } & Masculino & 169 & Sexo & Masculino & 203 \\
\hline & Femenino & 273 & & Femenino & 197 \\
\hline \multirow[t]{6}{*}{ Edad } & $18-24$ & 189 & Edad & $18-24$ & 108 \\
\hline & $25-34$ & 209 & & $25-34$ & 111 \\
\hline & $35-44$ & 18 & & $35-44$ & 9l \\
\hline & $45-54$ & 12 & & $45-54$ & 53 \\
\hline & $55-64$ & 14 & & $55-64$ & 25 \\
\hline & & & & 65 o más & 12 \\
\hline \multirow[t]{21}{*}{ Ocupación } & Estudiantes & 117 & Estudios & Sin estudios & 22 \\
\hline & Comerciantes & 80 & & Básicos & 23 \\
\hline & Oficios diversos & 59 & & Medio & 65 \\
\hline & Profesionistas & 50 & & Técnico & 46 \\
\hline & Amas de casa & 48 & & Licenciatura & 214 \\
\hline & Técnicos & 43 & & Posgrado & 30 \\
\hline & Maestros & 26 & & & \\
\hline & Empleados & 13 & Procedencia & Distrito Federal & 85 \\
\hline & Jubilados & 6 & & Colima & 40 \\
\hline & & & & Veracruz & 39 \\
\hline & & & & Tabasco & 31 \\
\hline & & & & Baja California & 30 \\
\hline & & & & Puebla & 28 \\
\hline & & & & Oaxaca & 27 \\
\hline & & & & Mérida & 21 \\
\hline & & & & Morelos & 19 \\
\hline & & & & Chihuahua & 19 \\
\hline & & & & Jalisco & 18 \\
\hline & & & & Tapachula & 17 \\
\hline & & & & San Cristóbal & 16 \\
\hline & & & & Venezuela & 10 \\
\hline
\end{tabular}


En el extremo opuesto, encontramos que los resultados más bajos se refieren al interés de la población en participar en la actividad turística (3.55), la intervención de las dependencias públicas y organizaciones que fomentan la actividad turística en el municipio (3.58) y al interés de la población en desarrollar la actividad turística en la región (3.62) (figura 1).

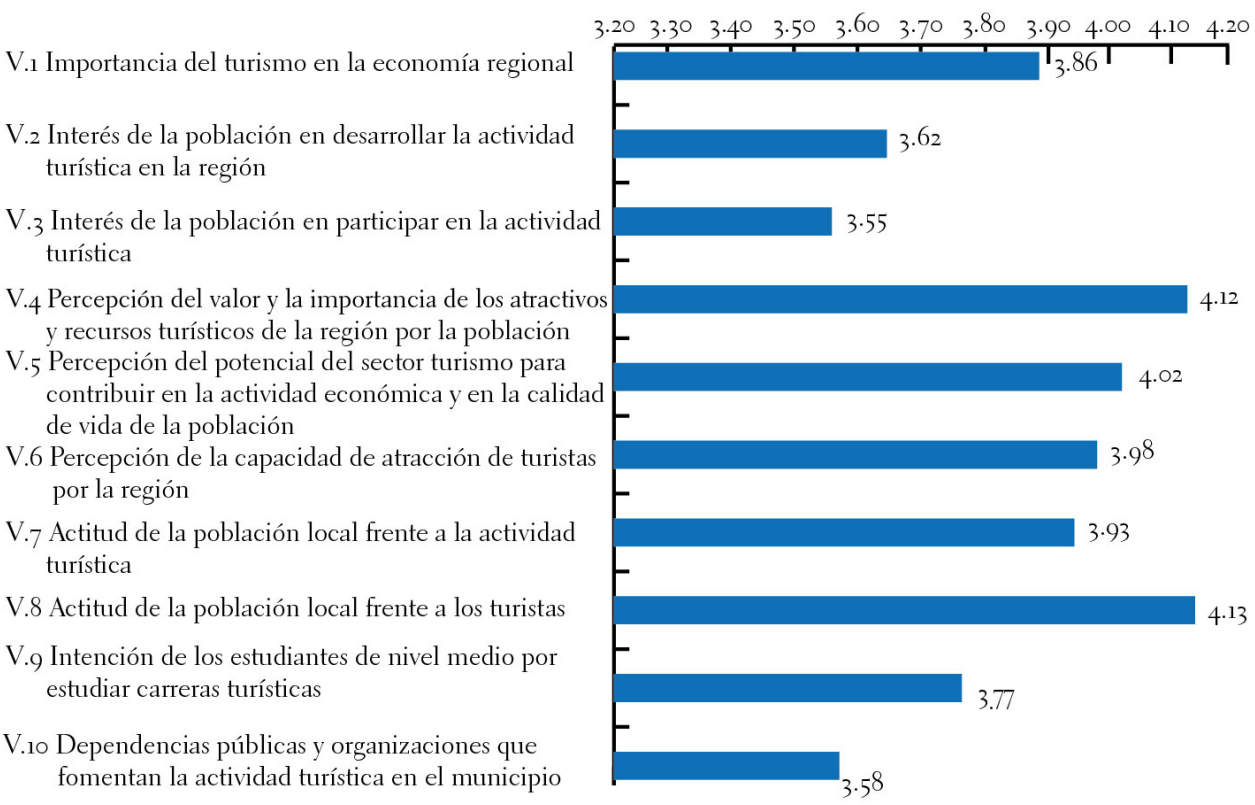

Figura 1. Concentrado de los resultados de encuestas a residentes

En el cálculo de la desviación estándar, con excepción de la variable 9, relativa al interés de los jóvenes por estudiar carreras turísticas, las respuestas de la encuesta a residentes resultan bastante consistentes, con poca dispersión, pues casi todos se ubican a menos de una desviación estándar de la media; en el polo opuesto, las dimensiones con menor grado de dispersión son las que se refieren a la actitud de la población frente a los turistas, con desviación estándar de 0.15 y, por otra parte, con resultados iguales en este apartado, se encuentran el interés de la población por participar en la 
actividad turística y la percepción del potencial del turismo para contribuir al desarrollo de la actividad económica y a la mejora de la calidad de vida de la población, con desviación estándar de 0.17 (cuadro 2).

\subsubsection{Encuesta a turistas}

Como se observa en la figura número 2, las respuestas de la encuesta a turistas resultan bastante menos optimistas que las respuestas de los residentes, y bastante más consistentes; en términos generales, las dimensiones propuestas para medir la vocación turística del municipio alcanzaría cuando mucho una calificación de 7.26 en una escala de 10; el resultado más elevado en esta encuesta se refiere a la percepción de la importancia del turismo en la economía regional (3.86), seguido por la capacidad natural de atracción de corrientes turísticas a la región (3.63) y a la actitud de la población local frente a los turistas (3.60).

En lo que se refiere a la desviación estándar, en el cuadro 3 puede observarse que las dimensiones que obtuvieron respuestas más consistentes son las que se refieren a la percepción del valor y la importancia de los atractivos y recursos turísticos de la región por los turistas, con una desviación estándar muy reducida (0.03), seguida por la actitud de la población local frente a los turistas (0.10) y la percepción del potencial del sector turismo para contribuir en la actividad económica y en la calidad de vida de la población (0.13). La dimensión relativa a la importancia del turismo en la economía regional resultó con la desviación estándar más elevada de todo el estudio, tanto en la encuesta a residentes como a turistas, con 0.78 . 


\section{Cuadro 2. Encuesta a residentes}

V1. Importancia del turismo en la economía regional (promedio)

1. El turismo es una de las actividades económicas más importantes de la región. $\quad 4.16$

2. Parte importante de los empleos e ingresos que se generan en la región provienen de la actividad turística.

3. La actividad turística juega un papel central en la economía regional.

4. Parte importante de las empresas y de las personas de la región se dedican a actividades relacionadas con el turismo.

Desviación estándar

V2. Interés en desarrollar la actividad turística en la región (promedio)

1. Numerosas organizaciones públicas y privadas están actualmente formulando proyectos turísticos en la región.

2. El turismo juega un papel central en los planes y proyectos de desarrollo regional.

3. Muchas personas y organizaciones apuestan actualmente al turismo como opción de $\quad 3.79$ desarrollo local.

Desviación estándar

$V_{3}$. Interés de la población en participar en la actividad turísica (promedio)

1. Si pudiera, me dedicaría a una actividad vinculada con el turismo.

2. Parte importante de la población se interesa en dedicarse a actividades vinculadas con el turismo.

3. Si pudiera, la mayoría de la población se dedicaría a trabajar en la industria turística.

4. En esta ciudad, muchas personas intentan obtener empleos en la industria turística.

5. Actualmente, en esta ciudad, muchas personas y empresas se interesan en invertir en proyectos turísticos.

Desviación estándar

1. La región cuenta con una cantidad importante de atractivos turísticos de gran valor. $\quad 4.06$

2. Los atractivos turísticos de la región permiten a nuestra ciudad competir como destino turístico de primer nivel.

3. Los atractivos turísticos de la región posibilitan a nuestra ciudad desarrollar su importante actividad turística.

Desviación estándar 


\section{Cuadro 2. Encuesta a residentes (continuación)}

V5. Percepción del potencial del turismo para contribuir en la economía (promedio)

1. La región cuenta con atractivos turísticos que, de ser desarrollados en todo su potencial, permitirían generar una importante actividad económica.

2. La región cuenta con atractivos turísticos que, en caso de ser desarrollados ubicarían a 4.06 nuestra ciudad entre los principales destinos turísticos del país.

3. Los atractivos turísticos de la región presentan un potencial que sólo espera que se pongan en operación los planes y proyectos de desarrollo turístico existentes para generar importantes beneficios económicos y sociales.

Desviación estándar

V6. Percepción de la región por los turistas (promedio)

1. Normalmente existen considerables flujos de turistas visitando la región por iniciativa $\quad 3.74$ propia, sin necesidad de realizar promoción.

2. Nuestra región tradicionalmente atrae corrientes turísticas de manera natural.

3. Debido a sus atractivos naturales y/o culturales, históricamente, nuestra región ha sido percibida por las personas de otras regiones como una zona turística a visitar.

Desviación estándar

$\mathrm{V}_{7}$. Actitud de la población local frente a la actividad turística (promedio)

1. La población de la zona considera que la actividad turística es muy positiva para el $\quad 4.01$ desarrollo socioeconómico local.

2. La población local presenta una actitud muy positiva frente a la actividad turística en $\quad 4.08$ la localidad.

3. La población percibe a las empresas y operadores turísticos como importantes contribuyentes al desarrollo socioeconómico local.

Desviación estándar

1. La población local recibe a los visitantes con gran hospitalidad.

2. La población local ve con muy buenos ojos a los turistas que nos visitan.

3. La población local considera que los turistas traen consigo beneficios y progreso.

4. La población local considera muy positiva la presencia de turistas en la localidad. 


\section{Cuadro 2. Encuesta a residentes}

\section{(finaliza)}

2. Las opciones académicas de turismo generalmente rechazan aspirantes.

3. Es necesario incrementar las plazas en las opciones académicas del área de turismo.

10.2 Dependencias del Ayuntamiento (direcciones, departamentos)

10.2.2 Fomento Económico

10.2.3 Turismo

10.2.4 Cultura

10.3.1 Canaco-Servytur

10.3.2 Canirac

10.3.3 Asociación de Hoteles, Agencias, etc.

10.3.4 Asociación de Agencias de Viajes o Touroperadores

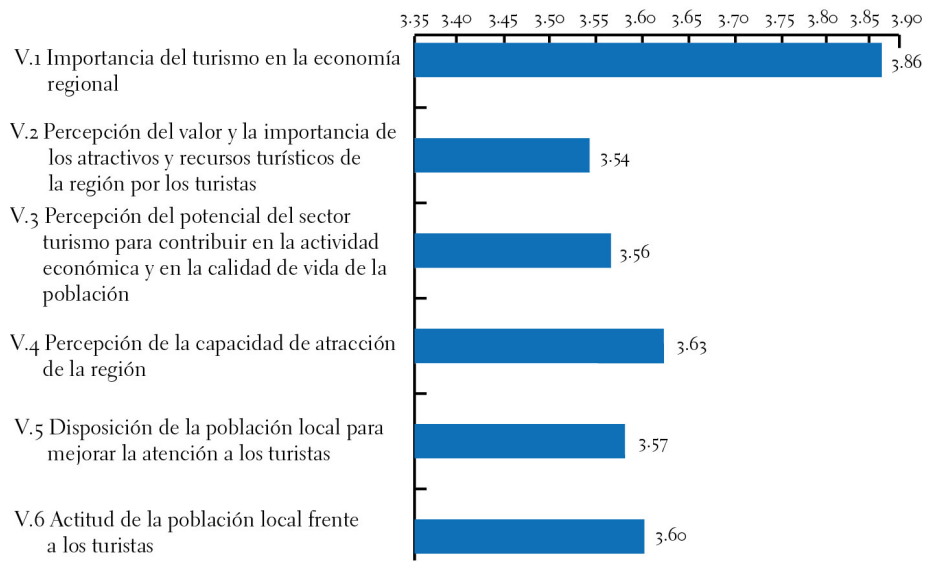

Figura 2. Concentrado de resultados de encuesta a turistas 


\section{Discusión}

La comparación de los resultados de las encuestas a turistas y residentes arroja algunos datos relevantes a primera vista; en primer lugar, los resultados de la encuesta a turistas presentan la mitad de la dispersión de los resultados de la encuesta a residentes, con una desviación estándar promedio de 0.11 frente a 0.22 ; si bien este último dato no resulta desmesurado, sí demuestra una menor consistencia en las respuestas. En los resultados generales, la encuesta a residentes presenta un promedio final de 3.86 frente a 3.63 de los turistas, con un diferencial de 0.23 entre ambos datos.

Tanto residentes como turistas coinciden en asignar la misma calificación a la importancia que el turismo reviste para la economía regional; en el otro extremo, curiosamente, los resultados de la percepción de la actitud de la población frente a los turistas presenta un resultado optimista entre los residentes, quienes se califican ellos mismos con un abundante 4.13 (cuadro 2), el resultado más elevado de toda la investigación, frente a un reservado 3.6 asignado por los turistas (cuadro 3), con un diferencial de 0.53 entre ambos datos, lo cual puede significar que la población local no demuestra una actitud tan positiva frente a los visitantes o, de la misma manera, que éstos no la perciben así; en ese mismo sentido, la percepción del valor y la importancia de los atractivos turísticos de la región por turistas y residentes presenta un diferencial similar, pues la población local asigna un valor de 4.12, frente a 3.54 asignado por los turistas, con resultados en ese mismo tenor en la percepción del potencial de la actividad turística para contribuir al desarrollo económico y a la calidad de vida de la población en la región, con un dato de 4.02 en la población frente a 3.56 de los turistas (cuadros 2 y 3 ).

Los resultados de la encuesta permiten establecer una diferenciación entre recursos turísticos y vocación turística: si bien la población local brinda una gran importancia al papel que la actividad turística juega en la economía regional, así como a la importancia y al valor de los atractivos turísticos y a la capacidad de atracción turística de la región, entre los resultados más bajos del estudio, en las encuestas a ambos tipos de actores, se encuentran el interés de 
Cuadro 3. Encuesta a turistas

Vı. Importancia del turismo en la economía regional (Promedio)

1. El turismo es una de las actividades económicas más importantes de la región.

2. Parte importante de los empleos e ingresos que se generan en la región provienen de la actividad turística.

3. La actividad turística juega un papel central en la economía regional.

4. Parte importante de las empresas y de las personas de la región se dedican a actividades relacionadas con el turismo.

Desviación estándar

0.78

V2. Percepción del valor y la importancia de los actractivos y recursos turísticos de la región por los turistas (Promedio)

1. La región cuenta con una cantidad importante de atractivos turísticos de gran valor.

2. Los atractivos turísticos de la región permiten a esta ciudad competir como destino turístico de primer nivel.

3. Los atractivos turísticos de la región posibilitan a esta ciudad desarrollar su importante actividad turística.

Desviación estándar

0.03

$V_{3}$. Percepción del potencial del sector turismo para contribuir en la actividad económica y en la calidad de vida de la población (Promedio)

1. La región cuenta con atractivos turísticos que, de ser desarrollados en todo su potencial, permitirían generar una importante actividad económica.

2. La región cuenta con atractivos turísticos que, en caso de ser desarrollados, ubicarían a nuestra ciudad entre los principales destinos turísticos del país.

3. Los planes y proyectos de desarrollo turístico existentes para generar importantes beneficios económicos y sociales.

Desviación estándar 


\section{Cuadro 3. Encuesta a turistas}

(finaliza)

$\mathrm{V}_{4}$. Percepción de la región por los turistas (promedio)

1. Normalmente existen considerables flujos de turistas visitando la región por iniciativa propia, sin necesidad de realizar promoción.

2. Esta región tradicionalmente atrae corrientes turísticas de manera natural. 3.66

3. Debido a sus atractivos naturales y/o culturales, históricamente, esta región ha sido percibida por las personas de otras regiones como una zona $\quad 3.82$ turística a visitar.

Desviación estándar

V5. Disposición de la población local para mejorar la atención a los turistas (promedio)

1. Puede percibirse que la población de la zona hace un esfuerzo importante por desarrollar la industria turística.

2. Puede percibirse que la población de la zona hace un esfuerzo importante por capacitarse para brindar una mejor atención a los turistas.

3. Puede percibirse que la población de la zona hace un esfuerzo importante por brindar una excelente atención de los turistas.

4. El personal que atiende a los visitantes cumple las expectativas generadas por la comunicación comercial y el prestigio del destino turístico.

Desviación estándar

V6. Actitud de la población local frente a los turistas (promedio)

1. La población local recibe a los visitantes con gran hospitalidad.

2. La población local ve con muy buenos ojos a los turistas que visitan la región.

3. La población local considera que los turistas traen consigo beneficios y progreso.

4. La población local considera muy positiva la presencia de turistas en la localidad.

Desviación estándar

Fuente: Elaboración propia 
la población en desarrollar la actividad turística y en participar en la actividad turística en la región, a los que pueden agregarse, por sus pobres resultados, las dimensiones relativas al liderazgo ejercido por los organismos empresariales y gubernamentales en el fomento al turismo y, por otra parte, en el poco interés de los jóvenes por cursar opciones académicas vinculadas al aprovechamiento turístico. Así, la población considera que en la región existen recursos turísticos y potencial de aprovechamiento para mejorar la situación económica y la calidad de vida de la población, pero existe poca disposición por parte de la población para participar en la actividad turística, así como un liderazgo muy limitado por parte de las organizaciones empresariales y gubernamentales.

\section{Conclusiones e implicaciones gerenciales}

Como se comentó, la investigación objetiva y sistemática de la vocación turística resulta, hasta el momento, un tema pendiente, pues si bien es cierto que el término se viene utilizando desde hace tiempo en diferentes ámbitos y modalidades de publicaciones, también es cierto que se ha empleado de manera metafórica, coloquial e imprecisa. Una de las aportaciones del presente trabajo consiste en el esfuerzo por medir empíricamente el constructo. Otro resultado que resulta oportuno destacar es que el estudio permite diferenciar entre recursos turísticos y vocación turística, entendiendo que la vocación turística se deriva esencialmente de la disposición de la población local y de las clases dirigentes para fomentar la actividad turística y participar en su desarrollo. También resaltan entre los resultados las diferencias entre las percepciones de las diferentes dimensiones de la vocación turística que se incluyeron en el estudio empírico por parte de la población local y los turistas; atendiendo a un enfoque de mercado, debe concederse un mayor peso a las percepciones de los turistas

Algunas de las recomendaciones gerenciales que pueden derivarse del presente estudio se orientan a señalar que no basta con disponer de recursos turísticos para alcanzar un aprovechamiento turístico eficiente en una región determinada, sino que el liderazgo de los organismos gubernamentales y empresariales resulta esencial, y no sólo por parte de los organismos del turismo, 
sino también por las dependencias y organizaciones de fomento económico en general, al igual que las de planeación, educación, seguridad y de gobierno local, por mencionar algunas, no es apropiado dejar recaer toda la responsabilidad en las dependencias de fomento al turismo, pues la actividad turística es multidisciplinaria, involucra a numerosos agentes económicos de muy diversas categorías. En este contexto, es importante destacar el papel que juegan las clases dirigentes en la conducción de los esfuerzos productivos de la población, moldeando sus inclinaciones y su disposición para optimizar el aprovechamiento de los diversos recursos naturales, económicos y culturales de cada región, entre los cuales los recursos turísticos pueden presentar un importante potencial de desarrollo. Entre las herramientas que pueden emplearse para promover un desarrollo turístico integral se encuentran los planes maestros de desarrollo turístico de largo plazo, elaborados en forma multidisciplinaria y participativa.

\section{Literatura citada}

Edgell, D. (1983). Viewpoint: USA and the international traveler. Tourism Management, 3, 308-310.

Gobierno del Estado de Chiapas. (2013). Comisión Estatal de Información Estadística y Geográfica de Chiapas. Turismo. Recuperado de http://www. ceieg.chiapas.gob.mx.

Guizzardi, A. y Mazzocchi, M. (2010). Tourism demand for Italy and the business cycle. Tourism Management, 31, 367-377.

Hankle, D. (2010). The psychological processes of discerning the vocation to the catholic priesthood: A qualitative study. Pastoral Psychology, 59, 201-219.

Holland, J. (1997). Making vocational choices: A theory of vocational personalities and work environments. Odessa, FL: Psychological Assessment Resources. 
Instituto Nacional de Estadística, Geografía e Informática (2009). Prontuario de información geográfica municipal de los Estados Unidos Mexicanos; Tuxtla Gutiérrez, Chiapas. Recuperado de http://www.inegi.org.mx Instituto Nacional de Estadística, Geografía e Informática (junio 2013). Perspectiva estadística Chiapas. Recuperado de http://www.inegi.org.mx Ishikawa, N. y Fukushige, M. (2007). Who expects the municipalities to take the initiative in tourism development? Residents' attitudes of Amami Oshima Island in Japan. Tourism Management, 28, 461-475.

Massidda, C. y Etzo, I. (2012). The determinants of Italian domestic tourism: A panel data analysis. Tourism Management, 33, 603-610.

Merriam-Webster (2012). Recuperado de http://www.merriam-webster.com/ Ministerio de Comercio Exterior y Turismo de Perú. (2012). Conceptos clave. Recuperado de http://www.mincetur.gob.pe/

Osborne, W. (1997). Career development, assessment, and counseling: Applications of the Donald E. Super C-Dac approach. Alexandrea: American Counseling Association. En Hankle, D. (2010). Pastoral Psychology, 59, 201-219.

Parsons, F. (1909/2008). Choosing a vocation. Whitefish: Kessinger. En Hankle, D. (2010). Pastoral Psychology, 59, 201-219.

Pearce, D. (1999). Tourism in Paris. Studies at the microscale. Annals of Tourism Research, 26(1), 77-97.

Petrizzi, R. (2011). El genios loci y la vocación turística de un destino. Recuperado de http://ramiropetrizzi.blogspot.mx/2011/05/el-genios-loci-y-lavocacion-turistica.html

Real Academia Española (2012). Diccionario de la lengua española $\left(22^{\circ}\right.$ ed.). Disponible en http://www.rae.es/

Ritchie, B. (1988). Consensus policy formulation in tourism. Measuring resident views via survey research. Tourism Management, 3, 199-214.

Roe, A. (1956). The psychology of occupations. Nueva York: Wiley, en Hankle, D. (2010). Pastoral Psychology, 59, 201-219. 
Schaefer, T. (1984). Professionalism. Foundation for Business Ethics Journal of Business Ethics, 3, 269-277.

Super, D. (1972). Vocational development theory: Reasons, positions, processes. En J. M. Whiteley y A. Resnikoff (Eds.). Perspectives on vocational development. Washington, D. C.: American Personnel and Guidance Association. En Bedeian, A. (1977). The roles of self-esteem and achievement in aspiring to prestigious vocations. Journal of Vocational Behavior, 11(1): 109-119.

Valencia, J. (2012). Diccionario de términos turísticos. Disponible en < http:// www.boletin-turistico.com/diccionarioturismo/ > 